\title{
Environmental geopolitics: an introduction to questions and research approaches
}

\section{Shannon O'Lear}

\section{Introduction}

Most people have a sense of what the field of geopolitics is: it has something to do with how place intertwines with power being exercised or challenged. Geopolitics is related to how decisions are made with a particular, place-related outcome or vision in mind: overcoming a boundary, expanding territory, or making sure that someone or something else does not threaten a boundary or a territory. Geopolitics might most easily be associated with states or countries and how they relate to each other over spatial issues such as the control of boundaries and territory. Yet there are other actors or interest groups beyond states, and there are spaces and places that are beyond, within, and between the spaces claimed by states. The field of geopolitics, then, considers far more than how states make place-related and spatial decisions and actions. It encompasses many kinds of struggle to control places and place-related activities - What kinds of things can happen here? Who is allowed to be here? Who gets to make those decisions? - and considers different actors, interest groups, voices, and perspectives on spatial activities and processes.

When geographers study geopolitics, a key focus is on geographical knowledge and how it is put to use for particular purposes. Geographical knowledge is not a single, universal set of rules or observations but instead reflects a specific understanding and perspective at a given time. For instance, how a farmer knows and understands a rural area to produce a particular crop reflects a different kind of familiarity with a place than how an urban planner might understand and value the same rural area as a place for urban expansion. A national-level transportation planner might understand and value that same rural area in an entirely different way as part of a larger network of roadways. Each of these perspectives has a different kind of geographic knowledge about this same rural area in terms of what makes this place important and how it is related to other places. Each of these perspectives represents a different set of priorities, but they may not all be able to pursue their agendas in this rural area at the same time. Geographers focus on geographic knowledge because it is a way to understand not only that there can be different ways to value and understand the same place, but also because it indicates the kinds of agendas that might come into conflict as spatial actions and decisions are being pursued. 
Environmental geopolitics draws attention to geopolitical knowledge and agendas that involve environmental features in making claims about why certain places, practices, or actions are important. Here again, "environment" can mean many different things. It might refer to the planetary climatic system, to rainforests, to oil reserves, to microbes, to agricultural harvests, or any number of features or processes. The tendency is to think of "the environment" as somehow natural and as separate from humans. However, this clear distinction is easily challenged with the consideration of how human systems and environmental systems have both been influenced and altered significantly through exchanges and interactions (Asdal et al. 2016, Swyngedouw 2010, Zizek 1991). "The environment" then, is a malleable category that can mean many different things depending on how it is understood and portrayed. Similar to geographic knowledge, there are many kinds of knowledge about environmental features. These different forms of knowledge reflect specializations and scales of focus ranging from atomic structure to cells to organisms to ecosystems to biogeophysical processes, and so forth.

Both geographical knowledge and environmental knowledge come into play when environmental features are entangled in geopolitical issues: climate change and human migration; armed conflict related to environmental resources; management of endangered species, water scarcity, and forest fires; environmental degradation and food supply distribution; environmental impacts of energy generation and consumption; and the list goes on. These entanglements of geopolitical and environmental processes have multiple dimensions, and they are frequently portrayed to highlight some aspects over others. Often, it is possible to find a political agenda underlying any particular story or narrative about the environment. That in itself is not a bad thing, and it can be valuable to see what kinds of agendas are drawing on environmental features and processes. This kind of consideration is useful because it can demonstrate how a portrayal of the environment is limited either intentionally or inadvertently to achieve a desired outcome.

Drawing from political geography, environmental geopolitics examines how spatial agendas from different political vantage points draw upon environmental concerns and objectives to justify actions or inactions. The purpose of this edited volume is to propose a critical approach to examining these perspectives and claims, to identify key research themes that could be usefully developed, and to showcase current work that demonstrates this approach. The objective of this volume is to energize and advance a subfield within geography and to illuminate neighboring, interdisciplinary fields of study such as critical security studies, science and technology studies, political ecology, environmental policy and law, development and health, environmental sustainability and justice, and regional and global studies.

The following section of this chapter provides a brief overview of geopolitics and makes the case for examining different forms of geopolitical discourse: narrative or text, practice, materiality, identity, or embodiment. Next, this chapter introduces three themes of environmental geopolitics and discusses each theme as a useful point of entry to analyze environmental geopolitical discourses. Finally, this 
chapter includes an overview of the chapters in this book and how each one demonstrates environmental geopolitical analysis. The conclusion provides a summary of key themes of the chapters and looks ahead to possible pathways forward in environmental geopolitics research.

\section{Geopolitics}

There is no single, one-size-fits-all geopolitics. Instead, geopolitical perspectives are like maps of the world from particular viewpoints. Where we stand and what we want shapes how we view the world. Specifically, geopolitical perspectives portray some places or spatial processes either as valuable or as some kind of threat. Geopolitics is evident, for instance, in arguments about expanding territorial control, responding to aggressive, spatial activity of other states or groups of people, or building or breaking down borders, physical or otherwise, that allow the containment or movement of some things but not others. Studying geopolitics, then, is a matter of examining arguments about or portrayals of the world in order to understand which places and processes are prioritized, why, and to what end.

If geopolitical perspectives are maps of the world highlighting areas of value or risk, then environmental geopolitical claims are like maps that include some aspect of environmental features to explain why we value particular places and spatial processes differently. Environmental geopolitical claims integrate environmental features into explanations about why action in, around, or against certain places is important for a certain outcome. For instance these claims may involve arguments in favor of protecting particular places such as rainforests or exploiting certain places such as mineral-rich sites. These may also be claims about enhancing environmental processes through spatial action (for example, land acquisitions for agricultural production) or about controlling environmental processes through management efforts (such as flood mitigation efforts or fishing regulations). Environmental geopolitical claims are evident in arguments about expediting the movement of environmental features such as resource commodities or about containing the movement of other environmental features such as vector-borne diseases. Other arguments point to environmental features or processes as causing a particular response (as in drought leads to mass human migration or scarce resources lead to conflict). Environmental geopolitical perspectives draw upon environmental features to explain human activity in general terms or to make claims about why action or inaction to affect particular places is important. Examining these perspectives and questioning assumptions underlying these arguments can lead to useful insights and alternative ways of defining and solving problems.

Geopolitical agendas have traditionally been studied through an examination of texts and narratives such as speeches and policy documents. Geopolitical discourse is also evident in other forms such as materialities, practices, and identities (O'Lear 2018). Materialities are tangible things constructed to reflect or promote a political agenda. Border walls, pipelines, or the establishment of a protected nature reserve 
are examples of materialities that say something about who is in power and how power is being exercised. Practices are things that we do or that we avoid doing. Examples of practices include how we make consumption decisions, how society adapts or does not adapt to new information and ideas, or how we adjust our behaviors with the introduction of new technologies. A fourth form of discourse is identity or embodiment. How we label ourselves or label and group other people is informed by our perspective and understanding of the world. All four forms of discourse reflect ways that power shapes our relationship with environmental features and provide rich avenues for analysis. Broadening the scope of analysis to include these different but sometimes overlapping forms of discourse encourages a creative, multi-textured investigation of geopolitical claims involving environmental features.

Of particular interest in examining discourse in any form is to investigate the kinds of knowledge and information that are called upon to stabilize and legitimize a discourse. Often times, discourses that explain or shape human-environment interactions draw from dominant forms of science - natural or physical science and technoscience, for instance - to support and promote claims. Recognizing the dominant role of science in supporting a discourse can help to highlight other ways of knowing that could offer different interpretations and alternative pathways forward.

\section{Three entry points for environmental geopolitics}

There are three persistent themes in environmental geopolitical arguments. Paying attention to these themes opens the possibility to comment on these geopolitical claims and understand who benefits from promoting a particular view or map of the world. These three themes offer points of entry to environmental geopolitical analysis. First, geopolitical arguments involving environmental features are not always clear about what the environment is. They tend to portray and represent environmental features selectively or through a limited scope. Second, these claims tend to overlook or obscure human agency. By presenting either sweeping claims about human-environment interactions or limited options for human response, these claims render dimensions of power invisible. Environmental features are certainly distributed unevenly over the earth's surface, but environmental geopolitical claims can be selective in recognizing how human actions have contributed to current conditions that exacerbate inequity, injustice, and insecurity. Third, geopolitical arguments involving environmental features tend to have a selective, spatial focus that may overlook deeper geographies of human-environment interactions and ways in which these relationships unfold differently according to nuances of place and context. Although physical sciences are built on a foundation of universal principles, human-environment interactions are better understood as having both broad categories of spatial patterns and contextually unique dimensions.

This section borrows from Environmental Geopolitics (O'Lear 2018) to introduce these three points of entry to environmental geopolitical analysis. Each entry 
point provides a way to look at dominant narratives or discourses about how environmental features or processes are in some way political. These entry points or observations are neither exhaustive nor exclusive. There are any number of approaches to examining environmental geopolitical discourses; these three share some overlap and complement each other. These points of entry are useful in structuring questions about dominant understandings of environmental geopolitics. They are:

1. Question assumptions about the role and meaning of the environment.

2. Inquire into how human agency, and particularly uneven power relationships, is portrayed or obscured in geopolitical claims about environmental issues.

3. Recognize ways in which selective, spatial focus, such as universal generalizations about environmental processes or place-specific, environmental situations, serve to legitimize particular perspectives or political interests.

These three entry points help to disentangle elements of geopolitical claims related to environmental features, and they can contribute to a more balanced understanding of environmental processes, political agendas, and the value of seeing contributing factors to these relationships at multiple, simultaneous spatial scales. Consider each observation in turn.

\section{Question assumptions about the role and meaning of the environment}

Representations of environmental features can only ever be partial and selective. A key idea of environmental geopolitics is that it can be useful to question how environmental features and processes are portrayed. What kinds of information are included in any given conversation about the environment? What kinds of features or processes are emphasized and explained, and which elements are not addressed? At what spatial scale is attention focused, and what kinds of relationships does that reveal or hide?

Take for instance global data on temperature. A global data set would seem to be as comprehensive and complete as it can get. Yet, there is not such a thing as a global thermometer to measure global temperature. Instead, global temperature - or any kind of global - data are generated by stitching together many local data sets usually through the use of complex computer algorithms (Edwards 2010). It is only through the use of high-speed computers that this sort of global view of temperature or ocean movement or weather systems is visible. Even then, there are limits to what the data reveal about conditions locally, globally, or any scale in between. How often were temperature readings taken and under what kinds of conditions? What can consistency or changes in temperature indicate on their own, or how are they used to generate models or more complex pictures of the environment when combined with other sorts of locally gathered but globally integrated data on, for instance, rainfall, ecosystem change, or other environmental processes? Clearly, even a global data set about the environment is partial and incomplete. 
Other representations of environmental features and processes may exude reliability in their specificity. An example is the now familiar graphic of peak oil. This graphic depicts oil production over time. The line of the graph is a steep bell curve indicating rapidly expanding productivity initially, hitting a peak of oil production, and then steeply cascading in later years as oil productivity quickly diminishes. This graphic was originally developed by M. King Hubbard - who worked for a major oil company - to depict oil production within a region or by a specific oil field. The graph's apparent scientific accuracy of geological deposits and oil production capacity make the graph compelling, and the message is straightforward: oil will continue to be plentiful until, suddenly, it is not. A littleknown aspect of the graph is that M. King Hubbard was deeply concerned about human population growth and was hoping to deter a sense of ease about resource availability to support a growing population (Hemmingsen 2010). Part of his motivation in developing this graphic was to alert people to imminent changes in energy supply.

Despite the apparent certainty of this graphic, there are actually quite a few unknowns related to oil productivity that render this graphic an unreliable representation of geological reality (Bridge 2010). Not only has the timing of the peak of oil production been debated (Hubbard predicted it would happen in the 1970s), there are different factors determining how much of the oil underground can realistically be extracted. Technology is one of those determining factors, and economics is another. At what price per barrel is oil worth recovering given current technology, demand, refining and transportation requirements, and so on? Politics are also involved; think about interstate relations, sanctions on oil sales from particular states, and different kinds of power that oil wealth can generate. More recently, climate justice advocates around the world have called for leaving oil in the ground as a way to limit the greenhouse gas-trapping capacity of an atmosphere with growing levels of fossil fuel remnants. Yet despite these factors that influence oil production and complicate questions of how much, when, and even whether or not oil is extracted from the earth's subsurface, the graphic of Peak Oil, as it is widely known, is still used to represent the reality of oil production. Although this graphic, with references to proven reserves and future discoveries, may seem to explain a lot about oil as an environmental feature, upon closer examination it actually raises more questions than it addresses.

Whatever environmental feature or process is under discussion, particularly as part of a geopolitical agenda, there is usually a great deal to be learned by looking beneath the surface of how "the" environment is being represented. By questioning assumptions about "the" environment - that global data reflect a full reality or that a particular image, graphic, or other representation offers a complete explanation - it is possible to get a better understanding of how that particular environmental feature or process is utilized or depicted for particular, geopolitical ends. 
2. Inquire into how human agency, and particularly uneven power relationships, is portrayed or obscured in geopolitical claims about environmental issues

Oftentimes, narratives about environmental and political entanglements begin with a particular, natural resource that seems to set the stage: diamond mines in Sierra Leone are leading to armed conflict; transboundary water supplies can lead to tensions between states; food shortages can lead to price spikes and social unrest; climate change-induced ice melt in Arctic waters will lead to increased shipping and fishing in the Arctic Ocean; and so on. The resource in question may be either abundant (diamonds, newly available ocean routes) or the resource may be scarce (food and water shortages); either way, these kinds of narratives can be compelling because they seem clear in cause and effect. These kinds of narratives all fall into a category of resource determinism. Resource determinism focuses on a natural resource or environmental feature to explain some social, political, or economic outcome. Yet this kind of argument is flawed because it glosses over the human systems and human agency that are involved in these situations. Environmental resources, themselves, do not cause conflict or stability, but they can exacerbate tensions in social, economic, and political systems. So, diamonds do not cause conflict, but the demand for diamonds and the way they have been marketed as a rare commodity make them valuable. It is this value that makes diamonds attractive as a means for financing armed conflict in some places that do not have political stability. Similarly, food shortages can certainly contribute to social tension, but underlying any food shortage are questions about who is in control of food prices, decisions about what kinds of crops are grown, and how food is distributed among a population.

Another way in which resource determinism is problematic is that it overlooks spatial dimensions of processes in question. Returning to the idea that diamonds cause conflict, attention quickly focuses on where that conflict is happening: Sierra Leone and other parts of Africa, for instance, where diamond mines happen to be in operation. It is important to zoom out, so to speak, to see how demand for diamonds in North America and Japan, for instance, generate interest in controlling diamond mines and the flow of diamonds to market. Even though armed conflict is not breaking out in posh jewelry shops in richer countries, the valuation of diamonds in places and societies far from diamond mines is a contributing factor to armed conflict. In the same way, food, water use, increased frequency of forest fires, energy provision, and other processes may most obviously happen or unfold in particular places, but that spatial understanding is only part of the story. With some investigation, these kinds of processes are usually shown to involve spatially vast networks in which environmental features or natural resources are interrelated with social, economic, and political systems. Resource determinism is helpful as an idea because it can serve as an alert that there is more to the story, both in terms of human agency and in terms of spatial connections.

This second entry point to examine environmental geopolitics takes that idea of questioning simplified arguments about the role of natural resources or environmental features in geopolitical narratives. It is a reminder that human agency in 
the form of social, economic, and political systems shapes how resources are used, extracted, transported, refined, distributed, priced, studied, managed, promoted, discouraged, and otherwise valued or devalued by societies. Bringing these kinds of elements of human-environment relations to the fore supports a better understanding of how or why a given geopolitical narrative portrays a situation from a selective perspective to promote a particular outcome.

\section{Recognize ways in which selective, spatial focus, such as universal generalizations about environmental processes or place-specific, environmental situations, serve to legitimize particular perspectives or political interests}

This third point of entry into environmental geopolitics picks up where the previous point of entry left off. In addition to recognizing that something happening or unfolding in one place is often connected to other places, it is also important to recognize the power of focusing an audience's attention on a limited spatial view. Geopolitics is about promoting a particular view of the world supported by a limited set of geographical knowledge. To be persuasive, a geopolitical narrative will focus on spatial elements that support the overarching view. A carefully cultivated, selective spatial focus may serve to obscure other aspects of the situation that challenge that view.

One example may be seen in arguments by corporate agribusiness in favor of supporting local food systems and the ability of people to feed themselves. Companies have promoted the use of genetically modified crops and other industrial inputs as the means for people, usually in less economically advanced places, to provide enough food for themselves. This narrative is repeated on company websites, reports, mission statements, and advertisements to describe the use of these inputs as positive and helpful for local communities. They make the case that these advanced, agricultural inputs will help to address food insecurity and support stability in these places and communities. These efforts may be described as "grainwashing" or a combination of brainwashing and greenwashing to make an activity seem both environmentally sustainable and socially responsible (Scanlan 2013). What these kinds of arguments obscure from view, however, is the global food production and distribution system in which these corporations play a significant and decisive role. By focusing attention on local communities and their (supposed) need for advanced agricultural inputs, this kind of narrative overlooks how the global food production system can actually contribute to localized food insecurity by destabilizing traditional food systems and preferences and shifting local communities toward a food system that prioritizes profit. The power dynamics of this kind of situation are particularly skewed since agribusinesses have developed collaborative support from governments, research universities, and think tanks. Messaging about local food systems emanating from these institutions is not necessarily in the best interest of local communities, but often those local communities do not have a voice or a platform from which to promote their own perspective. This example of corporate agribusiness promoting the local demonstrates selective, spatial focus to support a particular agenda or outcome. 
A somewhat inverse example of a selective spatial focus serving a particular agenda may be seen in claims about global climate change shifting the planet into a new geologic era, the Anthropocene. Many social scientists embrace the notion of the Anthropocene as a human-induced shift in the atmosphere, water bodies, and biology of the planet such that our very life-support system has become unstable and unreliable. The idea of the Anthropocene and a shift to unfamiliar circumstances is provocative and potentially useful. However, it is also an idea that should be treated with some caution. Statements or claims about how the entire planetary system is changing and that all of humanity will be affected suggest that everyone is in the same boat. That is not true in at least two ways. First, the most significant, contributing factor of climate change, the burning of fossil fuels, was caused by certain parts of the human population who used this energy to expand empires and industries as well as violence and destruction. The costs and benefits of this fuel use were (and continue to be) uneven. Second, the impacts of climate change such as increased heatwaves and droughts, and less predictable and more powerful storm systems, will not affect everyone in the same way. Richer people in some places will be able to buy their way out of harm or insecurity whereas people with fewer options may have little choice when conditions become difficult. References, then, to challenges faced by everyone on the planet prioritize and promote a global, all-encompassing view while overlooking the stark variations in cause and effect. Although the very word "Anthropocene" refers to all humans ("anthropo"), it might more usefully be a reminder of the variety of experiences and situations that humans face. As Gert Goeminne has aptly observed, "What is indeed going almost unnoticed . . . is that the apocalyptic climate scenarios paralyze the political struggle" (2010, p. 208).

\section{Overview of sections and chapters}

Most of the chapters in this book address one or more of these key themes or points of entry to environmental geopolitics, and the chapters are arranged loosely around these themes. Several chapters go beyond the organizational structure of the book to address issues related to this subfield such as methodology, policy implications, and possible areas for future work.

\section{Interpreting and measuring the environment}

Since a fundamental aspect of environmental geopolitics has to do with how we understand what the environment is, the chapters in this section ask questions about how we value, calculate, and assess the environment and why scientific methods and measures matter.

In their chapter "Getting the measure of nature: the inconspicuous geopolitics of environmental measurement", Brendon Blue and Marc Tadaki examine the "apparent objectivity of quantified data." Data on the physical environment are frequently used to support and promote particular views about how to manage, value, and engage with "nature," so it is important to understand how measurement 
may be selectively used to generate and perpetuate one view over another. Blue and Tadaki consider how measurements are valuable only insofar as they are accepted and agreed upon by scientific practice. In this way, measurements of the physical world are also social phenomena and constructs. As critical geopolitics seeks to question how power is maintained or challenged through the production of geographical knowledge, this chapter considers the role of scientific measurement in struggles over power and the representation of place, nature, and, in this case, the meaning of swimmable rivers.

Noella J. Gray, Leslie Acton and Lisa M. Campbell consider the intersection of science and ocean geopolitics in their chapter, "Science, territory, and the geopolitics of high seas conservation." They examine how the deployment of certain forms of measurement serves to reinforce practices of territorialization and the control over spatial representation. They draw on two case studies: international efforts to promote conservation on the high seas through the identification of marine protected areas, and challenges to conservation efforts focused on the inherently and spatially dynamic Sargasso Sea. Biologically significant ecosystems on the high seas lie beyond national jurisdiction, so efforts to protect these areas of biological diversity must somehow be made amenable to the spatial logics of sovereign states and territorial definitions and management. Similarly, the Sargasso Sea is an everchanging and always moving mass of aquatic life, and it, too, challenges traditional approaches to conservation efforts that tend to identify protected phenomena as something that may be clearly defined and spatially bounded. In both cases, these authors consider practices of territoriality as reflective of contested ways of knowing and interpreting the world.

In the third chapter in this section on interpreting and measuring the environment, Birgit Schneider and Lynda Olman assess the Global Forest Watch platform, which purportedly aims to monitor forest-related human activity and invites local input and feedback into its larger-scale view. In "The geopolitics of environmental global mapping services: an analysis of Global Forest Watch", these authors consider how this top-down representation of forests establishes a geopolitical framework in which certain political perspectives are embedded. Those perspectives are often at odds with local, situated perspectives and forms of engagement with the platform. In other words, they demonstrate how what appears to be a multi-scale system for monitoring forests is actually pre-structured to validate a technocratic approach to forest management and less of a means to support small-scale activism. How forests are defined, measured, and monitored reflects struggles over different understandings of the value and meaning of forests.

\section{Power, knowledge, and human-environment interactions}

The second point of entry to examining environmental geopolitics focuses on human agency and how it may be obscured in claims about natural resources and environmental features. Natural resources, as discussed earlier in this chapter, do not directly cause political, economic, and social outcomes but are often entangled 
in these human systems. The chapters in this section highlight how power takes many forms and is reflected not only in text and narratives, but also in materialities, practices, and identities - all of which provide promising avenues for analysis.

This section begins with Philippe Le Billon and Lauren Shykora's chapter, "Conflicts, commodities and the environmental geopolitics of supply chains." These authors step away from resource determinism's focus on either the absence or presence of resources and environmental conditions to draw attention to transnational flows of commodities. The supply chains for various commodities, themselves, are geopolitical constructs portrayed to consumers, selectively, as contributing to conflict or to peaceful conditions in particular places. Le Billon and Shykora look at three commodities associated with conflict or environmental degradation - oil, diamonds, and palm oil, and they also look at quinoa as an example of a commodity that is idealized as contributing to positive outcomes in both source locations as well as sites of consumption. Across all of these supply chains, particular interests and forms of power are reinforced through selective portrayals of material connections.

In his chapter "Underground geopolitics: science, race, and territory in Peru during the late nineteenth century", Matthew Himley provides a historical analysis of how geographical knowledge of subsurface earth science was intertwined with social geographies of economic development, race, and power in Peru. He demonstrates the importance of understanding how physical, subsurface features were studied and portrayed in ways that contributed to above-ground geographies of power and discrimination. Far from being objective facts about nature, science and scientific endeavors are shown to be extensions of geopolitics playing out on the earth's surface and used in selective ways to benefit some groups of people and processes over others.

Coleen A. Fox and Christopher Sneddon highlight different knowledges and experiences in their chapter "Local knowledges and environmental governance: making space for alternative futures in the Arctic circumpolar region and the Mekong River Basin.” Drawing examples from the Mekong River Basin and from Arctic locations, they highlight local perceptions of environmental features and processes and how those understandings come into tension with knowledges and processes at larger spatial scales. In these places, communities that are dependent on local resources are affected by priorities and decisions made at national and regional levels. The interests and knowledges of these communities are often overlooked by these larger-scale geopolitical processes. In the Arctic, climate change-induced melting ice is shifting traditional patterns of livelihoods while simultaneously attracting new actors interested in other forms of resource development. In the Mekong River Basin, upstream decisions to construct dams for hydroelectric power development serve the interests of powerful actors who do not take into account localized effects of dams on downstream communities. The chapter emphasizes not only the multiplicity of knowledges surrounding any particular environmental context, but also how the selective use of knowledge serves certain interests and reinforces power imbalances. 


\section{Overcoming selective spatial focus}

The third theme or point of entry into environmental geopolitics has to do with observing how a selective spatial focus can serve a particular geopolitical agenda. Environmental geopolitical analysis considers how environmental features are used to extend geopolitical arguments, so investigating the spatial scale at which environmental features are interpreted or obscured in order to reinforce claims to power is a defining aim of environmental geopolitics. The three chapters in this section are all focused on a particular place or region. They summarize results of grounded fieldwork or place-specific cartographic analysis. These three chapters are able to position their place-specific case studies into multiple spatial scales of activity to demonstrate the importance of selective spatial focus. Recognizing selective geographies in geopolitical claims about the environment creates potential to generate more just, inclusive, and forward-looking interpretations of our place with the environment.

In their chapter "The geopolitics of transportation in the melting Arctic," Frédéric Lasserre and Pierre-Louis Têtu challenge the popular idea that an increasingly ice-free Arctic Ocean will attract more international traffic through that ocean. Despite mass media speculation that a more accessible Arctic Ocean would lead to significant levels of commercial traffic taking advantage of shorter routes across the Arctic, these authors demonstrate that shipping traffic in the Arctic has taken a substantially different pattern. Not only has trans-Arctic shipping not significantly increased, localized traffic in support of terrestrial resource exploitation has notably increased in the number of trips. Without a clear understanding of what actually drives shipping patterns in Arctic regions, mainstream assumptions about impacts of this changing environment are inherently misleading.

Another approach to looking at multiple, intertwined spatial scales is demonstrated in "Environmental geopolitics of rumor: the sociality of uncertainty during northern Thailand's smoky season." In that chapter, Mary Mostafanezhad and Olivier Evrard look at the sociality of rumor in the context of seasonal air pollution, sometimes referred to as a haze crisis, in northern Thailand. In their fieldwork and ethnographic research, they discern distinct social groups who self identify as upland and lowland people from different regions of the country. These groups have different interpretations of the cause of the haze as well as its significance. In their chapter, these authors examine the kinds of evidence and knowledge brought to bear in these different, local narratives about the environment in which these social groups live. They find that elements of ethnicity, urban-rural interactions, and communication technologies contribute to the ways that these groups understand and explain the haze.

Taking a different look at the interrelatedness of spatial scales in resource extraction, Jesse Swann-Quinn focuses his chapter, "Digging deep: crossing scale in the Georgian mining industry," on mining in Georgia. Utilizing fieldwork, interviews, and document analysis, he considers the spatial politics and networks involved in mineral extraction practices that tie together global demand, transnational 
industrial interests, and local perceptions of mining's costs and benefits. Different actor groups create different spatial framings of environmental features and mining practices depending on how that group perceives and portrays advantages or negative impacts of these practices. Swann-Quinn looks at how these spatial scales are constructed differently by different interest groups associated with mining, yet these spatial framings of the mining industry do not fit neatly into discrete spatial scales or boxes. Instead, Swann-Quinn's analysis shows how political practices operate simultaneously at multiple spatial scales. The spatial dimensions of these different political pursuits reflect the geopolitical landscape of mining in Georgia.

\section{Final chapter and looking ahead}

The final chapter of this volume summarizes how each chapter contributes not only to the three key themes or entry point of environmental geopolitics but to the subfield of environmental geopolitics. The chapter also initiates a conversation among scholars in this field about how we might usefully move forward to generate meaningful questions about environmental geopolitics and address them in useful and creative ways. Of particular interest are dominant discourses about environmental features and their relationship to human systems and interests. Whether the topic is energy consumption, food riots, sustainable cities, disease vectors, land use change, conflict related to resources, logistics and environmental management, environmental measures and assessment, thinking globally or acting locally in a context of Anthropocenic change, environmental geopolitics encourages the careful examination of dominant discourses and the geographic and environmental knowledge and representations embedded in them. What kinds of material realities, identities, and practices do these dominant ways of thinking promote as valuable and important, and what kinds of material realities, identities, and practices are minimalized, overlooked, or obscured by these same ways of thinking? How do policymakers, public figures, popular culture, and people as citizens and as consumers perpetuate or potentially challenge dominant or mainstream narratives that shape how we understand, discuss, and engage with environmental features? These are key questions underlying environmental geopolitics, and the chapters in this book provide examples of how scholars and researchers are creatively addressing those questions.

\section{References}

Asdal, Kristin, Tone Druglitro, and Steve Hinchliffe (eds) (2016), Humans, Animals and Biopolitics: The More-Than-Human Condition, London, UK and New York, NY: Routledge.

Bridge, G. (2010), "Geographies of peak oil: The other carbon problem," Geoforum, 41(4), 523-30.

Edwards, Paul N. (2010), A Vast Machine: Computer Models, Climate Data, and the Politics of Global Warming, Cambridge, MA: The MIT Press.

Goeminne, G. (2010), “Climate policy is dead, long live climate politics!," Ethics, Place E Environment: A Journal of Philosophy E Geography, 13(2), 207-14. 
Hemmingsen, E. (2010), "At the base of Hubbert's Peak: grounding the debate on petroleum scarcity," Geoforum, 41(4), 531-40.

O’Lear, Shannon (2018), Environmental Geopolitics, Boulder, CO: Rowman \& Littlefield.

Scanlan, S. J. (2013), "Feeding the planet or feeding us a line? Agribusiness, 'grainwashing' and hunger in the world food system," International Journal of Sociology of Agriculture E Food, (3), 357-82.

Swyngeouw, Erik (2010), "Trouble with nature: 'ecology as the new opium for the masses," in Jean Hillier and Patsy Healy (eds), The Ashgate Research Companion to Planning Theory: Conceptual Challenges for Spatial Planning, Burlington, VT: Ashgate, pp. 299-318.

Zizek, Slavoj (1991), Looking Awry: An Introduction to Jacques Lacan Through Popular Culture, Cambridge, MA: The MIT Press. 